\title{
An Appraisal on the Source-to-Sink Relationship in Plants: an Application of Desorption Electrospray Ionization Mass Spectrometry Imaging
}

\author{
Julia R. L. Freitas, ${ }^{a}$ Pedro H. Vendramini, ${ }^{b}$ Júlio O. F. Melo, ${ }^{c}$ Marcos N. Eberlin ${ }^{b}$ and \\ Rodinei Augusti ${ }^{*}, a$ \\ ${ }^{a}$ Departamento de Química, Universidade Federal de Minas Gerais, \\ 31270-901 Belo Horizonte-MG, Brazil \\ ${ }^{b}$ Laboratório ThoMSon de Espectrometria de Massas, Instituto de Química, \\ Universidade Estadual de Campinas, 13083-970 Campinas-SP, Brazil \\ 'Departamento de Química, Universidade Federal de São João del-Rei, \\ 35701-970 Sete Lagoas-MG, Brazil
}

\begin{abstract}
Amino acids/ureides and carbohydrates are the main nutrients for the plants growth. These metabolites are continuously translocated through the plant organism via well-known transportation mechanisms. The well-established source-to-sink relationship involves the transfer of these nutrients from mature (source) to young (sink) leaves. Desorption electrospray ionization mass spectrometry imaging (DESI-MSI) is used herein to determine the spatial distribution of amino acids/ureides and carbohydrates in the imprintings of Mentha $\times$ piperita $\mathrm{L}$. leaves at three distinct maturation stages: young, expanding, and mature. Hence, chemical images of some typical carbohydrates (glucose, sucrose, sorbitol/mannitol) and free amino acids/ureides (phenylalanine, leucine, histidine, aspartate, asparagine, tyrosine, glutamate, allantoic acid) clearly point to a source-tosink relationship, as the young leaves are the final destination for some of these key metabolites. These results therefore reveal the high potential of DESI-MSI to investigate biochemical processes in plants, a still underexplored area.
\end{abstract}

Keywords: desorption electrospray ionization mass spectrometry imaging, nutrient transport in plants, amino acids, carbohydrates, peppermint leaves, distinct stages of maturation

\section{Introduction}

Plants are classified as autotrophic living beings because they are able to synthesize their own food supply. In this process, roots extract water and mineral ions from the soil whereas leaves use $\mathrm{CO}_{2}$ and sunlight for photosynthesis. Together, these processes produce the required nutrients for plant growth. In plants, two specialized systems conduct nutrients for long distances: xylem and phloem. Xylem transports water and amino acids/ureides from root to leaves, whereas phloem exports the biosynthesized nutrients from leaves to other tissues. ${ }^{1,2}$

In a process known as ontogenesis, young leaves undergo substantial metabolic, physiological, and structural transformation. Because their photosynthetic system is still incomplete, young leaves import nutrients (carbohydrates,

*e-mail: augusti.rodinei@gmail.com amino acids and a wide range of other biosynthesized molecules) from mature leaves and roots to maintain their high biosynthetic activity. ${ }^{1,3}$ The connection between mature and young leaves (net exporters and importers of biosynthesized nutrients, respectively) is usually called source-to-sink relationship and occurs through the phloem. ${ }^{2-8}$ When young leaves import amino acids and ureides from the roots, the connection is usually called root-to-shoot transportation and occurs via the xylem. ${ }^{3}$

Studies on the synthesis, mobility and storage of metabolites within plants have been conducted for decades. Several methodologies have been used for this purpose, such as isotopic labeling $\left({ }^{15} \mathrm{~N}\right.$ and $\left.{ }^{14} \mathrm{C}\right)$, radioactive labeling, electron and transmission electron microscopy, normal and fluorescence microscopy, laser-scanning microscopy, nuclear magnetic resonance, gamma irradiation detection, and imaging techniques based on positron emission tomography and matrix assisted laser desorption 
ionization mass spectrometry (MALDI-MS) ${ }^{9-13}$ However, some of these methodologies are expensive, laborious and/or time consuming. Moreover, none of them present similar performance comparing to desorption electrospray ionization mass spectrometry imaging (DESI-MSI) regarding the huge amount of information potentially attainable in a quite short period of time.

Mass spectrometry (MS) is an analytical technique used to detect, identify and quantify a large range of substances, usually organic compounds. The identification is made via the evaluation of the mass/charge $(\mathrm{m} / \mathrm{z})$ ratio of ionized species. ${ }^{14}$ Currently, modern ionization techniques, such as desorption electrospray ionization (DESI), have allowed the generation of ions under ambient conditions. ${ }^{15}$

In DESI, a potential of several kilovolts applied on an electrolytic solution (usually a mixture of protic solvents) and under pneumatic assistance of a nebulizer gas generates an electrospray plume, which is comprised mainly by charged microdroplets. This jet is then directed onto the sample surface where the analytes are deposited. These are transferred into the microdroplets when the ionization process takes place. A subsequent evaporation of solvent and Coulomb fission release the ionized analytes into the gas phase. These are subsequently inserted into the mass spectrometer to be analyzed. This is the very well-known droplet-pickup mechanism that operates under the usual DESI conditions. DESI possesses several advantageous features, such as easy operation, large flexibility, and high sensitivity. It applies to both large and small molecules allowing analysis of samples at ambient conditions with minimal (if any) pretreatment. ${ }^{14-19}$ In addition, easily ionizable analytes can be detected by DESI even at very low concentrations with high specificity. ${ }^{18}$

Mass spectrometry imaging (MSI) provides both chemical information and spatial distribution of compounds in a surface. ${ }^{20,21}$ Images by DESI-MS (DESI-MSI) are generated using a mobile station where samples are deposited and directly scanned. The probe of DESI is fixed whereas the mobile station moves in the $\mathrm{x}$ and $\mathrm{y}$ directions to perform the analysis of the entire sample. The $\mathrm{x}$ axis comprises the distance that the mobile station travels at a constant and predefined speed, while the ionization source acquires the data at each point (pixel). The y axis is composed by numerous lines with spacing previously defined between them. In the end, the DESI probe scans the entire sample surface obtaining the spatial distribution of a variety of analytes with high specificity. Proper softwares are used to convert the mass spectra data into a 2D spatially-resolved ion images. An image shows the distribution of a specific ion in a given surface whereas the color scale reveals its intensity in a particular spot. ${ }^{14,17,22}$ The steps of DESI-MSI process are schematically represented in Figure 1.

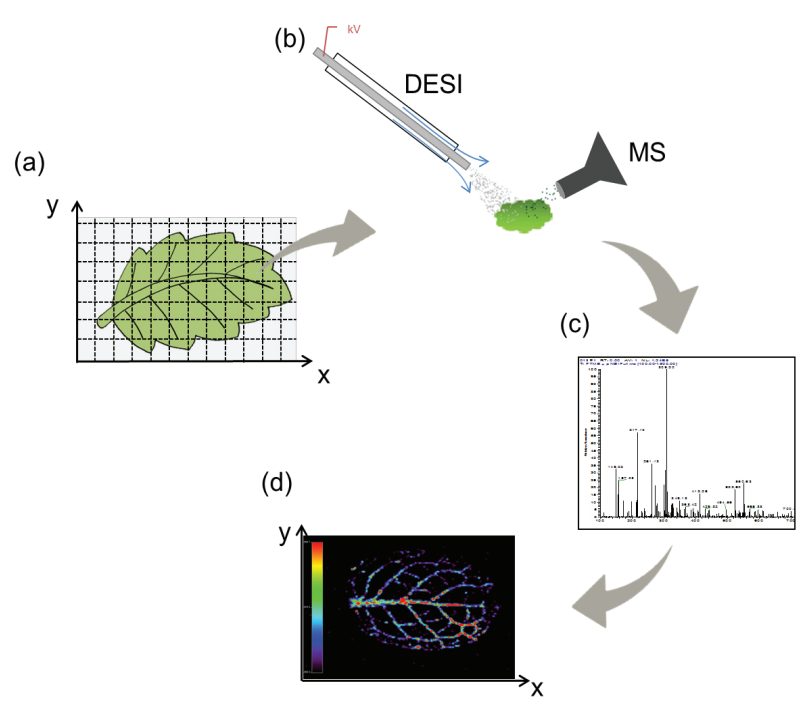

Figure 1. Sequential steps in a DESI-MSI procedure: (a) tracing lines on the entire sample surface in the y direction (each line is composed by a number of spots or pixels); (b) scanning the entire surface (line after line) with the fine spray (stream of charged microdroplets); (c) acquiring and storing the mass spectra (one for each pixel); (d) conversion of the mass spectra data into $2 \mathrm{D}$ images.

DESI-MSI has been employed in several studies, which include tumors detection in biological tissues, ${ }^{22,23}$ forensic analysis, ${ }^{24-26}$ drugs detection, ${ }^{27}$ and plant metabolomics. ${ }^{13,28}$ A couple of publications dealing with the application of DESI-MSI on plant metabolomics have also been reported, including unprecedented information regarding physiological role and metabolites distribution. ${ }^{20}$ For instance, some interesting studies dealing with this subject have been conducted, such as: (i) monitoring of metabolic changes in sprout that result from a pathogen invasion;29 (ii) detection of chlorophyll degradation products in senescent plants, ${ }^{30}$ (iii) distribution of metabolites (mainly long chain fatty acids) in leaves, flower cuticles, and petals $;^{20}(i v)$ distribution of pesticides on the surface of leaves and in cross sections of plant stem and leaves; ${ }^{31}$ (v) elucidation of marine natural product defenses. ${ }^{32}$

Peppermint (scientific name: Mentha $\times$ piperita $\mathrm{L}$.) is an herbaceous plant that belong to the family of lamiaceae being a hybrid of the species Mentha aquatica $\mathrm{L}$. and Mentha spicata L. Peppermint is under cultivation from tropical to temperate climate of America, Europe, Asia and South Africa being used worldwide owing to its valuable essential oil.$^{33}$ It is one of the most important and popular aromatic medicinal plants, and is easily available in herbal markets. The metabolism of terpenes in peppermint leaves has been extensively evaluated, including studies on the differences in the monoterpene composition as a function 
of leaf age.$^{6,34}$ However, no studies regarding the presence and distribution of carbohydrates, amino acids, flavonoids, phenolic compounds in any tissue of this plant have been conducted.

This paper aims to demonstrate that desorption electrospray ionization mass spectrometry imaging (DESI-MSI) can be successfully applied to appraise the transport of nutrients in plants. As a proof-of-principle, the source-to-sink relationship in plants is investigated by verifying the spatial distribution of some free amino acids/ureides and soluble carbohydrates in leaves of Mentha $\times$ piperita $\mathrm{L}$. (peppermint) at three distinct maturation stages: mature, expanding and young.

\section{Experimental}

Material

HPLC grade methanol and toluene were purchased from Tedia (Rio de Janeiro, Brazil). Polytetrafluoroethylene (PTFE) membrane (pore size $0.45 \mu \mathrm{m}$ and $47 \mathrm{~mm}$ diameter) was acquired from Allcrom (São Paulo, Brazil).

\section{Sample material and preparation}

Shrubs of Mentha $\times$ piperita $\mathrm{L}$. were purchased at a local store and identified by their morphological features and database. Three leaves from the same branch at different development stages (young, expanding, and mature) were collected. The young (17 mm length) leaf was positioned in the orthotropic orientation. On the other hand, the expanding (21 $\mathrm{mm}$ length) and mature $(38 \mathrm{~mm})$ leaves were oriented in the plagiotropic position (Figure S1, Supplementary Information).

After harvest, the leaves were wiped with toluene to remove surface wax. This procedure was adopted to achieve a superior DESI performance. The leaves were dried in air and placed between two PTFE membranes, which were then fixed in a homemade press. The membranes were submitted to a high pressure for approximately 60 seconds to generate the imprintings, which were fixed in the mobile platform and scanned by the DESI-MSI apparatus (Figure S1, Supplementary Information). In all cases, only the abaxial side of each leaf was analyzed. During this process, the main metabolites of the leaves are transferred to the PTFE membrane, a nearly-perfect flat surface, which is then analyzed by DESI-MSI. This procedure avoids the attainment of distorted images due to the irregular leaf surface. Finally, the distance between the leaf surface and the DESI capillary tip (Figures 1 and S1) was kept unchanged during the analysis of the three samples. This preventive measure was adopted aiming at avoiding undesirable fluctuations in the absolute intensities of the ions in the mass spectra that could cause the acquisition of distorted data and, as a consequence, leading to misinterpretations of the generated images.

\section{DESI-MSI analysis}

DESI-MS imaging analyses were conducted on a commercial Thermo Scientific Q Exactive (Thermo Fisher Scientific, Germany) mass spectrometer coupled to an Omni Spray Ion Source 2-D (Prosolia, Indianapolis, USA) mobile platform. Prior to the imaging experiments, some key geometrical and source parameters were optimized in order to maximize signal intensity. Typical instrumental parameters were as following: capillary voltage $(5 \mathrm{kV})$ and temperature $\left(300^{\circ} \mathrm{C}\right)$. Methanol was used as the spray solvent, which was delivered at a flow rate of $10 \mu \mathrm{L} \mathrm{min}^{-1}$. Mass spectra were acquired in the full scan mode, in the positive and negative ion modes, over the mass range from $\mathrm{m} / \mathrm{z}, 100$ to 1000 . Images were collected with a resolution of $200 \mu \mathrm{m}$, in a scan rate of $740 \mu \mathrm{m} \mathrm{sec}^{-1}$. The MS spectra were processed by the Qual Browser Xcalibur software, and the collected data were converted into image files using the Firefly Data Conversion software (version 2.1.05). Finally, the images were viewed with the assistance of the BioMAP software (version 3.8.04).

\section{Results and Discussion}

Taking into account that the mass spectra were acquired in the full scan mode ( $\mathrm{m} / \mathrm{z}$ range from 100 to 1000$)$, several images from distinct ions were generated. However, to investigate the source-to-sink relationship in plants, subject of the present study, only the changes in the content and spatial distribution of some key metabolites (some free amino acids/ureides and soluble carbohydrates) in the peppermint leaves at three distinct maturation stages (young, expanding and mature) were assessed by applying DESI-MSI. Amino acids/ureides and carbohydrates were chosen as central metabolites because they are notorious sources of nitrogen and carbon, respectively, and play a vital role during the growth stage of several plant tissues, especially leaves. The data for the amino acids/ureides and carbohydrates that were identified upon evaluation of the mass spectrometry data, recorded directly from the peppermint leaf imprintings, are displayed in Table 1.

Moreover, as previously stated in the Experimental section, to attain images with superior quality, the peppermint leaves were washed with toluene to remove 
Table 1. Amino acids/ureides and carbohydrates detected in the peppermint leaf imprintings upon DESI-MSI analysis

\begin{tabular}{|c|c|c|c|c|c|}
\hline \multirow{2}{*}{ Ionic species } & \multirow{2}{*}{ Symbol } & \multirow{2}{*}{ Formula } & \multicolumn{2}{|c|}{ Exact mass } & \multirow{2}{*}{ Error / ppm } \\
\hline & & & Theoretical & Experimental & \\
\hline [phenylalanine $-\mathrm{H}]^{-}$ & phe & $\mathrm{C}_{9} \mathrm{H}_{10} \mathrm{NO}_{2}$ & 164.07061 & 164.07074 & 0.822 \\
\hline$[\text { leucine }-\mathrm{H}]^{-}$ & leu & $\mathrm{C}_{6} \mathrm{H}_{12} \mathrm{NO}_{2}$ & 130.08626 & 130.08617 & -0.655 \\
\hline$[\text { histidine }-\mathrm{H}]^{-}$ & his & $\mathrm{C}_{6} \mathrm{H}_{8} \mathrm{~N}_{3} \mathrm{O}_{2}$ & 154.06110 & 154.06116 & 0.370 \\
\hline [aspartate] $^{-}$ & asp & $\mathrm{C}_{4} \mathrm{H}_{6} \mathrm{NO}_{4}$ & 132.02913 & 132.02909 & -0.335 \\
\hline [asparagine $-\mathrm{H}]^{-}$ & asn & $\mathrm{C}_{4} \mathrm{H}_{7} \mathrm{~N}_{2} \mathrm{O}_{3}$ & 131.04512 & 131.04505 & -0.524 \\
\hline$[\text { tyrosine }-\mathrm{H}]^{-}$ & tyr & $\mathrm{C}_{9} \mathrm{H}_{10} \mathrm{NO}_{3}$ & 180.06552 & 180.06575 & 1.279 \\
\hline$[\text { glutamate }-\mathrm{H}]^{-}$ & glu & $\mathrm{C}_{5} \mathrm{H}_{8} \mathrm{NO}_{4}$ & 146.04478 & 146.04477 & -0.029 \\
\hline [allantoic acid $-\mathrm{H}]^{-}$ & all & $\mathrm{C}_{4} \mathrm{H}_{7} \mathrm{~N}_{4} \mathrm{O}_{4}$ & 175.04618 & 175.04641 & 1.307 \\
\hline$[\text { hexose }+\mathrm{K}]^{+\mathrm{a}}$ & hex & $\mathrm{C}_{6} \mathrm{H}_{12} \mathrm{O}_{6} \mathrm{~K}$ & 219.02655 & 219.02635 & -0.897 \\
\hline$[\text { sucrose }+\mathrm{K}]^{+}$ & suc & $\mathrm{C}_{12} \mathrm{H}_{22} \mathrm{O}_{11} \mathrm{~K}$ & 381.07937 & 381.07961 & 0.630 \\
\hline $\begin{array}{l}{[\text { mannitol }+\mathrm{K}]^{+}} \\
{[\text {sorbitol }+\mathrm{K}]^{+}}\end{array}$ & man & $\mathrm{C}_{6} \mathrm{H}_{14} \mathrm{O}_{6} \mathrm{~K}$ & 221.04220 & 221.04210 & -0.437 \\
\hline
\end{tabular}

${ }^{a}$ Hexose refers to isomeric carbohydrates with six carbon atoms in their structure (glucose, fructose, galactose, and mannose).

waxy cuticles from their surface previously to the imprinting step. These waxy cuticles are composed mainly by appendages, known as trichomes, which are reservoirs of essential oils. Probably because of that, essential oils were not detected in any of the mass spectrum recorded neither in the positive nor in the negative modes.

Precise and well-defined images were obtained for all ions displayed in Table 1. The images for the identified amino acids/ureides and carbohydrates are shown in Figures 2 and 3, respectively. To ensure a reliable comparison that allows for the attainment of accurate and correct conclusions, spots with the same color in the images of the three leaves (young, expanding and mature) denote roughly the same absolute intensity of a given ion, as observed in the corresponding mass spectra. Moreover, the red and black spots in the ionic images of the three leaves reveal the sites where a given metabolite is found with its maximum and minimum relative content, respectively.

The chemical structures of the ions displayed in Table 1 were proposed based on the comparison between the values of the experimental and theoretical masses of the ionic species derived from the amino acids/ureides (deprotonated forms, negative ion mode) and carbohydrates (potassium adducts, positive ion mode), which are well-known metabolites typically found in several plant tissues, mainly in leaves. This was possible because of the high resolution and precision of the mass analyzer (orbitrap) employed in the present study. Note that small errors were verified for all the identified ionic species, which varied within a narrow range from -0.897 to $1.279 \mathrm{ppm}$, for the potassium adduct of hexose and the deprotonated form of allantoic acid, respectively (Table 1). Some examples of mass spectra in the negative and positive ion modes are provided as Supplementary Information (Figures S2 and S3, respectively).

\section{Nitrogen transport}

During the ontogenesis, young leaves are in a higher metabolic activity, so they constitute the major sink for nitrogen. Roots taken up inorganic nitrogen to convert it into nitrogenated organic compounds, mainly amino acids and ureides. In sequence, the nitrogen compounds are exchanged via phloem to sink organs. The main amino acids found in the phloem are aspartate, glutamate, asparagine, and glutamine, whereas the major ureides are allantoin and allantoic acid. ${ }^{1,3,8,35}$ Young leaves contain from two to four fold more nitrogen than mature leaves and this content decreases as the leaves age. That is because growing leaves demand a huge amount of protein for growing. ${ }^{36,37}$

Table 1 displays the amino acids and ureides detected in the peppermint leaves, for which appropriate and discernible images were generated upon DESI-MSI application. Figure 2 shows the chemical images for each of these identified amino acids/ureides, generated directly from the imprintings of the peppermint leaves at the three distinct development stages. Pictures showing the three leaves, the homemade press, a typical imprinting, the mobile platform and the DESI apparatus are displayed as Supplementary Information (Figure S1).

The chemical images show remarkable differences in the distribution of the amino acids in each type of leaf. Among the essential amino acids, a not so remarkable difference in the content of phenylalanine (Figure 2a: phe) and leucine (Figure 2b: leu) in the three types of leaves can 


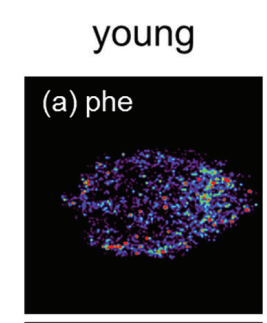

expanding
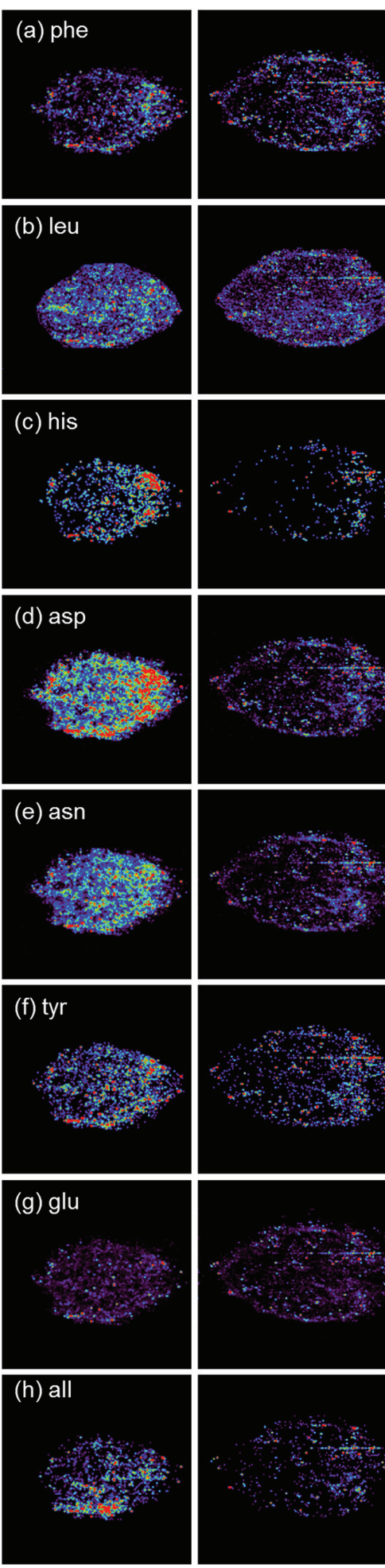

$0 \%$
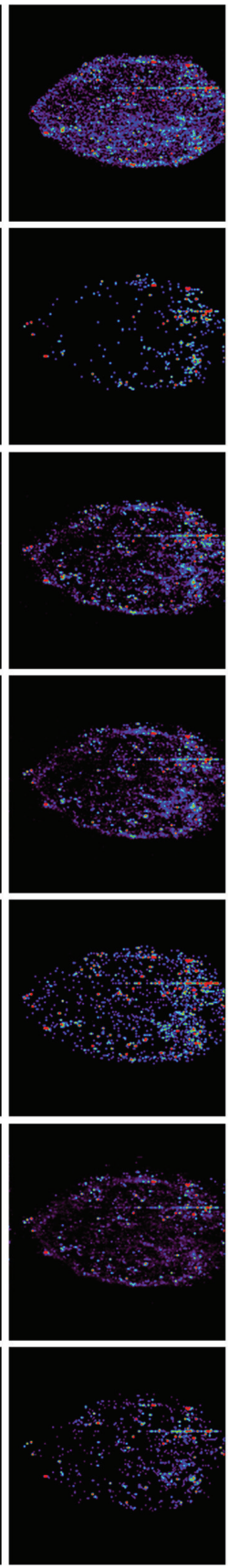
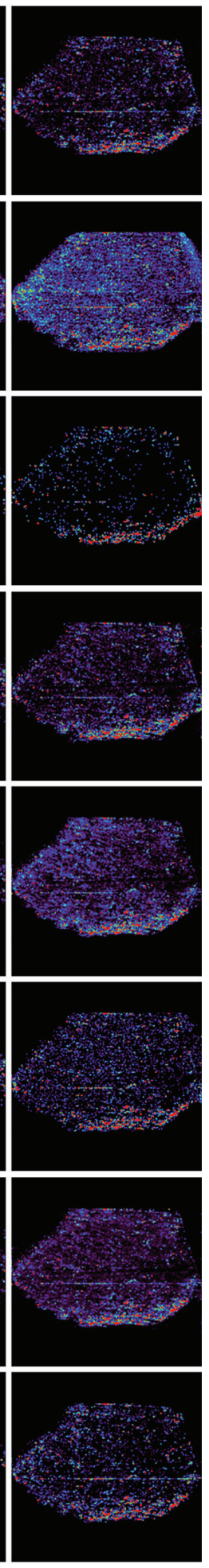

$100 \%$ mature

Figure 2. Chemical images of the free amino acids/ureides detected in the Mentha $\times$ piperita L. leaves at three different growth stages, sequentially young, expanding and mature: (a) phenylalanine (phe); (b) leucine (leu); (c) histidine (his); (d) aspartate (asp; (e) asparagine (asn); (f) tyrosine (tyr); (g) glutamate (glu); (h) allantoic acid (all).

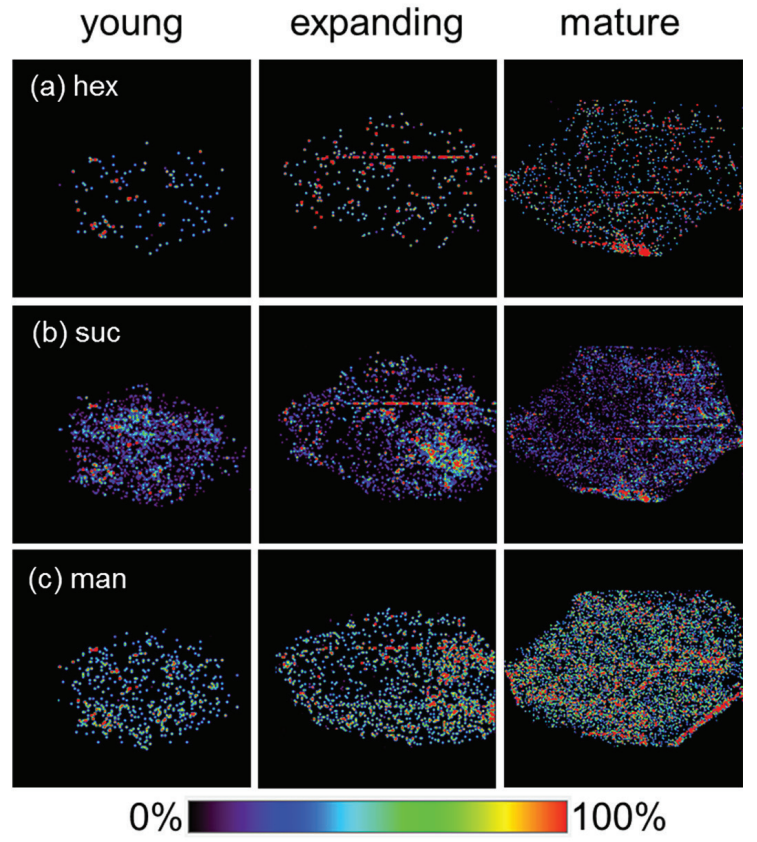

Figure 3. Chemical images of soluble carbohydrates detected in the Mentha $\times$ piperita $\mathrm{L}$. leaves at three different growth stages, sequentially young, expanding and mature: (a) hexose (hex); (b) sucrose (suc); (c) mannitol/sorbitol (man).

be visualized. The higher number of red and blue/green spots seem to indicate the higher content of these amino acids in the young leaf in comparison to the two other samples. The images also indicate a nearly-homogeneous distribution of these metabolites throughout the surfaces, excepting for phenylalanine that appears to be more concentrated at the edges of each leaf. In a great contrast, the content of the essential amino acid histidine (his) dropped significantly in the expanding and mature leaves in comparison to the young leaf (Figure 2c).

For the non-essential free amino acids aspartate (asp) and asparagine (asn) a similar scenario than that verified for histidine is clearly visualized. Hence, Figure $2 \mathrm{~d}$ shows the spatial distribution of aspartate in the three leaves. The highest number of red spots indicates the remarkable presence of aspartate in the young leaf. Note that this amino acid is barely detectable in the expanding and mature leaves. This finding is reasonable, because aspartate is a metabolically-reactive amino acid that is transported via the phloem and xylem and used as a nitrogen donor in several aminotransferase reactions. ${ }^{3}$ Regarding the amino acid asparagine, its main function in plants is transport and storage of nitrogen. Asparagine is transferred to young leaves directly from roots and mature leaves by the xylem and phloem, respectively. ${ }^{36}$ The results displayed in Figure 2e fully confirm this assumption: although asparagine is detectable in the three peppermint leaves, its presence is much more notable in the young leaf. 
Furthermore, note that asparagine is more concentrated at the edges of the mature leaf, which seems to indicate that these are the storage sites for this amino acid. A similar behavior (although not so remarkable) was also observed for tyrosine (Figure 2f: tyr), whose content decreased concomitantly with the increase of the leaf maturation age.

It is known that glutamate (glu) is not strongly absorbed by the stem tissue. Instead it moves with the xylem sap into mature leaves, where it is metabolized or loaded into the phloem for re-transport to young leaves or other plant tissues. ${ }^{8}$ The results displayed in Figure $2 \mathrm{~g}$ seems to corroborate such previous finding as this amino acid is homogeneously distributed throughout the three samples but without a clear evidence for the predominance in any of them.

Allantoic acid is a ureide that plays an important role in storage and translocation of nitrogen in several plant species. Previous studies demonstrated that this compound is produced by roots and transported to other plant tissues, where it is metabolized for re-assimilation into amino acids. ${ }^{3}$ As revealed by the images displayed in Figure $2 \mathrm{~h}$ and as equally verified for some of the other evaluated amino acids, the content of allantoic acid in the three types of samples corroborate the source-to-sink relationship as its content is clearly higher in the young leaf than in the other two samples.

\section{Carbohydrates transport}

Carbohydrates were detected as their potassium adducts in the Mentha $\times$ piperita $\mathrm{L}$. leaves rather than in their protonated forms (Table 1). That is probably due to the high content of potassium in the phloem sap. ${ }^{1}$ The chemical images obtained for the identified carbohydrates in each leaf, i.e., hexose, sucrose, and mannitol/sorbitol (see Table 1), are displayed in Figures $3 a, 3 b$, and 3c, respectively.

Figure 3 a exhibits the images generated for the potassium adducts of hexoses (glucose, fructose, galactose, and mannose, which are isomeric compounds and thus undistinguishable by mass spectrometry) (Table 1). These images reveal the differences in the intensity and distribution of these carbohydrates throughout the leaf structure according to the growth stage. In the young leaf, for instance, the presence of hexoses seems to be restricted to a few areas. For the expanding leaf, however, these metabolites appear in a higher number of spots and with a more homogeneous distribution. Finally, the image of the mature leaf is remarkably different compared to the young one: the hexoses are spread throughout the whole surface and a much higher number of red spots are clearly distinguishable.
These results confirm the changes experienced by leaves during the growth period. Mature leaves, which produces carbohydrates at a maximum photosynthetic rate, produce higher amounts of hexoses whereas young leaves have no efficient photosynthetic machinery thus producing a lower amount of this metabolite. , $^{2,5,6,38}$

Figure $3 \mathrm{~b}$ shows the spatial distribution of sucrose (Table 1) in the three leaves. These images reveal a roughly homogeneous distribution of this metabolite throughout the three types of leaves. Hence, sucrose is produced in the older leaves and then exported to the young leaves, where it is stored and metabolized to produce energy for growth. For the mature leaf, sucrose appears to be concentrated at the primary vein, as visualized in the no-normalized image for the $[\text { sucrose }+\mathrm{K}]^{+}$ion (Figure S4), probably an exporter site of this metabolite. .,6,34,39-41 $^{-1}$

The physiological functions of the isomeric mannitol and sorbitol, identified by their potassium adducts (Table 1), include storage of reduced carbon and assistance for carbohydrates carrying via the phloem. ${ }^{42,43}$ The chemical images obtained for the peppermint leaf imprintings reveal that these compounds are mainly present in the expanding and mature leaves (Figure 3c). These findings seem to corroborate previous data regarding physiology of plants because sorbitol and mannitol are synthesized exclusively in older leaves due to lack of proper enzymes in young leaves..$^{41,42}$ Moreover, this result is corroborated by previous reports that state that sorbitol and mannitol tend preferentially to be stored in older leaves rather than transported to younger counterparts. ${ }^{42}$ The small content of these polyols in young leaves is probably due to the transport from mature and intermediate leaves via the source-to-sink relationship. Moreover, in the non-normalized image of the mature leaf these compounds are mainly concentrated in the primary and secondary veins (Figure S5).

Other oligosaccharides commonly present in the phloem sap are raffinose and stachyose. However, possible ionic species derived from these carbohydrates were not detected in the mass spectra; as a consequence, no discernible images could be generated.

\section{Conclusions}

Physiological processes in leaves change continuously since the early stages up to maturity. The high metabolic activity in young leaves requires large concentrations of nitrogen (mainly) and carbon for their growth and development. Traditional techniques, such as fluorescence and radioactive isotope-labeling, normally used to visualize transport and storage of nutrients, are unable to furnish specific information about the metabolites present in a 
given tissue. Because DESI-MSI can reveal the spatial distribution of ionizable metabolites in leaves (and in other tissues as well), the source-to-sink mechanism of nutrient transport in plants could be appraised. This methodology can therefore provide key information regarding other biochemical processes within plant cells. Studies on these interesting possibilities are underway in our laboratory.

\section{Supplementary Information}

Supplementary information (imprinting methodology, mass spectra data, non-normalized images) is available free of charge at http://jbcs.sbq.org.br as PDF file.

\section{Acknowledgments}

The authors thank the financial support from the Brazilian agencies CAPES, FAPEMIG, CNPq and are also grateful to the sponsorship from Pró-Reitoria de Pesquisa of the Universidade Federal de Minas Gerais.

\section{References}

1. Lalonde, S.; Tegeder, M.; Throne-Holst, M.; Frommer, W. B.; Patrick, J. W.; Plant, Cell Environ. 2003, 26, 20.

2. Turgeon, R.; BioScience 2006, 56, 10.

3. Tegeder, M.; J. Exp. Bot. 2014, 65, 1865.

4. Bachmann, M.; Matile, P.; Keller, F.; Plant Physiol. 1994, 105, 11.

5. Kriedemann, P. E.; Kliewer, W. M.; Harris, J. M.; Vitis 1970, 9,8 .

6. Maffei, M.; Scannerini, S.; Phytochemistry 1992, 31, 6.

7. Lin, Z. F.; Ehleringer, J.; Photosynthetica 1982, 16, 6.

8. Dickson, R. E.; Ann. Sci. For. 1989, 46, 17.

9. Truernit, E.; J. Exp. Bot. 2014, 65, 1681.

10. Ruuhola, T.; Ossipov, V.; Lempa, K.; Haukioja, E.; Chemoecology 2003, 13, 95 .

11. Jeong, M. L.; Jiang, H.; Chen, H. S.; Tsai, C. J.; Harding, S. A.; Plant Physiol. 2004, 136, 3364.

12. Pate, J. S.; Soil Biol. Biochem. 1973, 5, 11.

13. Heyman, H. M.; Dubery, I. A.; Phytochem. Rev. 2015, 15, 297.

14. Cooks, R. G.; Ouyang, Z.; Takats, Z.; Wiseman, J. M.; Science 2006, 311, 1566.

15. Takats, Z.; Wiseman, J. M.; Gologan, B.; Cooks, R. G.; Science 2004, 306, 471.

16. Rao, W.; Celiz, A. D.; Scurr, D. J.; Alexander, M. R.; Barrett, D. A.; J. Am. Soc. Mass Spectrom. 2013, 24, 1927.

17. Ifa, D. R.; Wiseman, J. M.; Song, Q.; Cooks, R. G.; Int. J. Mass Spectrom. 2007, 259, 8.

18. Eberlin, L. S.; Ifa, D. R.; Wu, C.; Cooks, R. G.; Angew. Chem., Int. Ed. 2010, 49, 873.
19. Takats, Z.; Wiseman, J. M.; Cooks, R. G.; J. Mass Spectrom. 2005, 40, 1261.

20. Li, B.; Hansen, S. H.; Janfelt, C.; Int. J. Mass Spectrom. 2013, $348,15$.

21. Wu, C.; Dill, A. L.; Eberlin, L. S.; Cooks, R. G.; Ifa, D. R.; Mass Spectrom. Rev. 2013, 32, 218.

22. Eberlin, L. S.; Ferreira, C. R.; Dill, A. L.; Ifa, D. R.; Cooks, R. G.; Biochim. Biophys. Acta 2011, 1811, 946.

23. Angolini, C. F.; Vendramini, P. H.; Araujo, F. D.; Araujo, W. L.; Augusti, R.; Eberlin, M. N.; de Oliveira, L. G.; Anal. Chem. 2015, 87, 6925.

24. Tang, H.-W.; Lu, W.; Che, C.-M.; Ng, K.-M.; Anal. Chem. 2010, 82,5 .

25. Morelato, M.; Beavis, A.; Kirkbride, P.; Roux, C.; Forensic Sci. Int. 2013, 226, 10.

26. Correa, D. N.; Zacca, J. J.; Rocha, W. F.; Borges, R.; de Souza, W.; Augusti, R.; Eberlin, M. N.; Vendramini, P. H.; Forensic Sci. Int. 2016, 260, 22.

27. D’Alvise, J.; Mortensen, R.; Hansen, S. H.; Janfelt, C.; Anal. Bioanal. Chem. 2014, 406, 3735.

28. Boughton, B. A.; Thinagaran, D.; Sarabia, D.; Bacic, A.; Roessner, U.; Phytochem. Rev. 2016, 15, 445.

29. Tata, A.; Perez, C. J.; Hamid, T. S.; Bayfield, M. A.; Ifa, D. R.; J. Am. Soc. Mass Spectrom. 2015, 26, 641.

30. Muller, T.; Oradu, S.; Ifa, D. R.; Cooks, R. G.; Krautler, B.; Anal. Chem. 2011, 83, 5754.

31. Gerbig, S.; Brunn, H. E.; Spengler, B.; Schulz, S.; Anal. Bioanal. Chem. 2015, 407, 7379.

32. Esquenazi, E.; Dorrestein, P. C.; Gerwick, W. H.; Proc. Natl. Acad. Sci. U. S. A. 2009, 106, 7269.

33. Chauhan, R. S.; Kaul, M. K.; Shahi, A. K.; Kumar, A.; Ram, G.; Tawa, A.; Ind. Crops Prod. 2009, 29, 654.

34. Voirin, B.; Bayet, C.; Phytochemistry 1996, 43, 8.

35. Amiard, V.; Morvan-Bertrand, A.; Cliquet, J.-B.; Billard, J.-P.; Huault, C.; Sandström, J. P.; Prud'homme, M.-P.; Can. J. Bot. 2004, 82, 1594.

36. Bauer, A.; Urquhart, A. A.; Joy, K. W.; Plant Physiol. 1977, 59, 5.

37. Kursar, T. A.; Coley, P. D.; Biotropica 1991, 23, 11.

38. Dantas, B. F.; Ribeiro, L. S.; Pereira, M. S.; Rev. Bras. Frutic. 2007, 29, 6 .

39. Turgeon, R.; Webb, J. A.; Planta 1976, 129, 5

40. Turgeon, R.; Annu. Rev. Plant Physiol. Plant Mol. Biol. 1989, $40,20$.

41. Loescher, W. H.; Marlow, G. C.; Kennedy, R. A.; Plant Physiol. 1982, 70, 5.

42. Loescher, W. H.; Physiol. Plant. 1987, 70, 553.

43. Nadwodnik, J.; Lohaus, G.; Planta 2008, 227, 1079.

Submitted: March 3, 2017

Published online: June 8, 2017 